\title{
Inflammatory pseudotumor of the kidney: a case report
}

\author{
Abdelhak Khallouk ${ }^{1}$, Youness Ahallal ${ }^{1 *}$, Mohammed Fadl Tazi ${ }^{1}$, Hinde Elfatemi ${ }^{2}$, Elmehdi Tazi ${ }^{3}$, \\ Jalaleddine Elammari ${ }^{1}$, Mohammed Jamal Elfassi ${ }^{1}$ and Moulay Hassan Farih ${ }^{1}$
}

\begin{abstract}
Introduction: Inflammatory pseudotumors, also known as inflammatory myofibroblastic tumors, are uncommon benign tumors of unknown etiology which may develop at several anatomical sites. In the urogenital tract, inflammatory pseudotumor usually affects the urinary bladder or the prostate. Inflammatory pseudotumor of the kidney is very rare. It is considered as a reactive inflammatory lesion that features very good prognosis.
\end{abstract}

Case presentation: We present the case of a 57-year-old Moroccan man who presented with a two-month history of gross hematuria and left lumbar pain. Imaging investigations revealed a left kidney mass and pathological examination of the nephrectomy specimen showed an inflammatory pseudotumor.

Conclusion: As the preoperative definitive diagnosis of such a tumor is not possible, surgery is advised because only pathological examination of the nephrectomy specimen can establish the diagnosis with certainty. From one case report and literature review, the authors suggest a diagnostic and therapeutic strategy for the management of this rare tumor.

\section{Introduction}

Inflammatory pseudotumor is a rare benign condition of unknown cause. As far as we know, less than 20 cases have been reported in the English literature. It is important to report such rare benign renal tumors in order to determine their reliable characteristics and avoid performing unnecessary nephrectomies that increase the risk of chronic kidney disease. It can be seen in various organs. Originally described in the lungs, a renal location is extremely rare [1]. As inflammatory pseudotumor of the kidney usually mimics renal cell carcinoma, the preoperative diagnosis remains difficult and it is only made through pathological examination of the tumor. We report a case of inflammatory pseudotumor of the kidney; our patient presented with a renal mass and was treated with radical nephrectomy.

\section{Case presentation}

A 57-year-old Moroccan man presented with a twomonth history of gross hematuria and left lumbar pain. There was no past history of calculous disease or flank

\footnotetext{
* Correspondence: dryouness@gmail.com

'Department of Urology, Hassan II Teaching Hospital, Fes, Morocco

Full list of author information is available at the end of the article
}

pain. He had been smoking 40 cigarettes a day for the past 35 years. The physical and basic paraclinical examinations were normal. Ultrasonography revealed an $8 \mathrm{~cm}$ size heterogeneous mass of his left kidney. A contrastenhanced computed tomography $(\mathrm{CT})$ scan revealed a huge cystic tumor on the left kidney $(9.0 \times 6.5 \times 5.0 \mathrm{~cm}$ in size). It was slightly enhanced with contrast, suggesting a malignant tumor such as renal cell carcinoma (Figure 1). Radical nephrectomy was therefore performed under the diagnosis of renal cell carcinoma. Histopathological examination resulted in the lesion being diagnosed as an inflammatory myofibroblastic tumor, in which spindle cells were admixed with variable amounts of extracellular collagen, lymphocytes, plasma cells and siderophages (Figure 2 and 3). Immunostaining was positive for vimentin and HHF-35 and focally positive for smooth muscle actin.

The postoperative course was uneventful and our patient is disease-free after a follow-up of 14 months.

\section{Discussion}

Renal inflammatory pseudotumor (RIP) is very rare. It affects individuals of both sexes and is seen in a wide range of age groups [2]. First described in the lung

\section{Biomed Central}




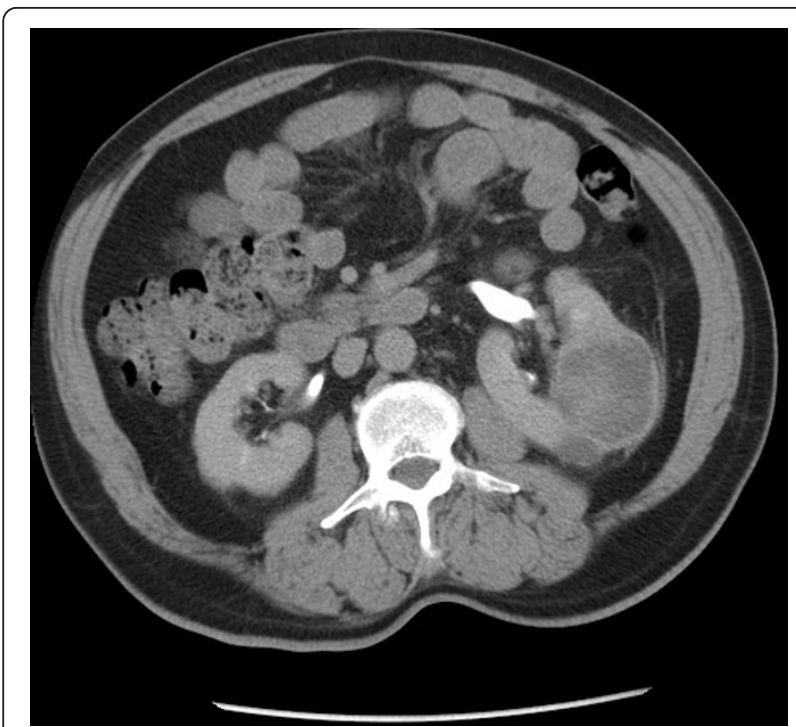

Figure $1 \mathrm{CT}$ scan showing a huge cystic tumor of the left kidney.

which is the most common site of involvement, RIP has been described as a benign lesion that mimics malignancy [3]. Differential diagnoses include malignant tumors such as renal cell carcinoma, sarcomatoid renal cell carcinoma, inflammatory fibrosarcoma, malignant fibrous histiocytoma, low grade neurogenic tumor, myxoid leiomyosarcoma and non-malignant tumors such as angiomyolipoma, xanthogranuloma pyelonephritis and plasma cell granuloma $[4,5]$. The pathogenesis of RIP is still controversial. The inflammatory reaction may be secondary to trauma, surgery, infection or an autoimmune process. Some cases could be related to EpsteinBarr virus infection as some authors reported positivity

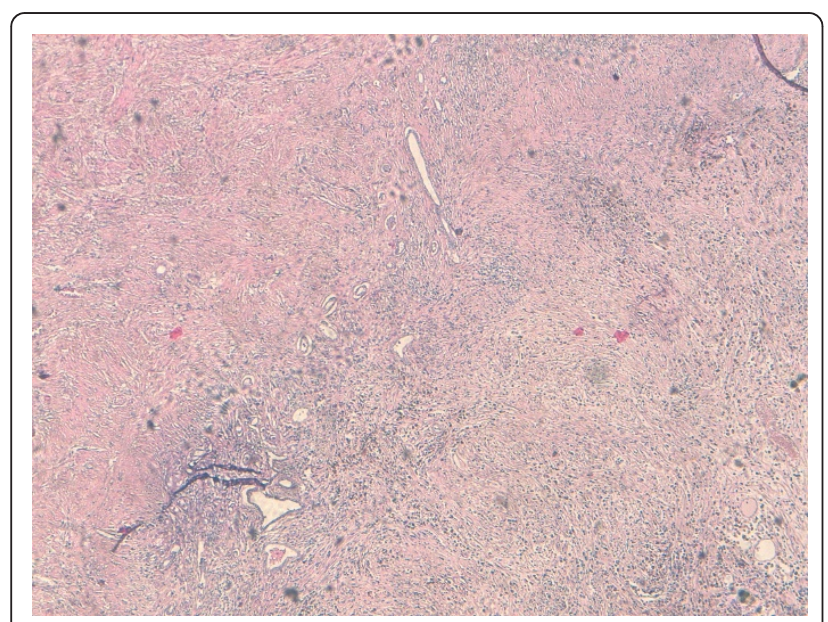

Figure 2 Photomicrograph showing dense collagen fibrous tissue and inflammation with cellular zone consisting of spindle cells $(\mathrm{HES} \times 5)$.

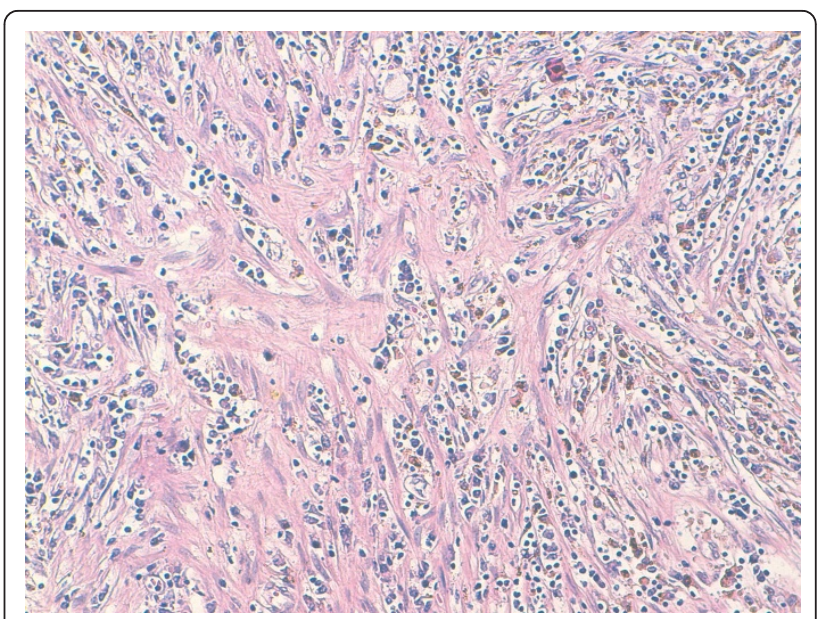

Figure 3 Photomicrograph showing area of myofibroblastic proliferation with plasma cells and siderophages (HES $\times 20$ ).

for Epstein-Barr virus latent membrane protein, especially in the liver and spleen [6,7].

Patients with RIP usually present with lumbar pain and hematuria. Physical examinations and radiological investigations are often inconclusive. RIP can be seen as a hypo- or heterogeneous echoic mass on sonography, a well-defined hypoechoic mass with intratumoral vascularity on enhanced power Doppler sonography, a lowattenuation mass on $\mathrm{CT}$, and hypovascular lesion on magnetic resonance imaging (MRI) [8].

We initially approached our case as renal cell carcinoma due to our patient's symptoms (hematuria and left flank pain) together with CT findings. Some authors reported malignancy associated with inflammatory pseudotumors [9] and it is difficult to make a preoperative diagnosis because symptoms and imaging findings are not specific. It is therefore appropriate to presume the given renal mass to be a renal cell carcinoma and to perform nephrectomy (be it radical or partial). Most diagnoses have been made after surgical intervention [3].

Histological examination is of particular importance to ensure appropriate patient management because RIP can be confused with both reactive process and malignant tumor [10]. RIP consist of a proliferation of spindle cells admixed with various amounts of lymphoplasmacytic infiltrate. Immunohistochemical studies support the myofibroblastic nature of this lesion, with consistent expression of vimentin and smooth muscle actin. These tumors are strongly positive for cluster of differentiation 34 molecule (CD34) reactivity. The architectural appearances vary and have been described as a patternless pattern [10].

\section{Conclusion}

RIP is an extremely rare neoplasm of uncertain biological potential. The preoperative diagnosis remains 
difficult, despite progress in medical imaging and often requires surgical exploration.

We report a case of RIP treated with radical nephrectomy because the tumor was presumed to be malignant. Histological examination of the specimen confirmed RIP. It is therefore mandatory to carry out good histological examination to make the diagnosis and to assure appropriate patient management.

\section{Consent}

Written informed consent was obtained from the patient for publication of this case report and any accompanying images. A copy of the written consent is available for review by the Editor-in-Chief of this journal.

\section{Author details}

${ }^{1}$ Department of Urology, Hassan II Teaching Hospital, Fes, Morocco.

2Department of Pathology, Hassan II Teaching Hospital, Fes, Morocco.

${ }^{3}$ Department of Medical Oncology, National Institute of Oncology, Rabat,

Morocco.

\section{Authors' contributions}

AK, MFT and YA have been involved in drafting the manuscript. ET analyzed and interpreted the patient data regarding its oncological features. HE analyzed the pathological features of the specimen. MJE and MHF have given final approval of the version to be published. All authors read and approved the final manuscript.

\section{Competing interests}

The authors declare that they have no competing interests.

Received: 31 December 2010 Accepted: 24 August 2011

Published: 24 August 2011

\section{References}

1. Coffin $C M$, Watterson J, Priest JR, Dehner LP: Extrapulmonary inflammatory myofibroblastic tumor (inflammatory pseudotumor). A clinicopathologic and immunohistochemical study of 84 cases. Am J Surg Pathol 1995, 19(8):859-872.

2. Park SB, Cho KS, Kim JK, Lee JH, Jeong AK, Kwon WJ, Kim HH: Inflammatory pseudotumor (myoblastic tumor) of the genitourinary tract. AJR Am J Roentgenol 2008, 191(4):1255-1262.

3. Ryu KH, Im CM, Kim MK, Kwon D, Park K, Ryu SB, Choi C: Inflammatory myofibroblastic tumor of the kidney misdiagnosed as renal cell carcinoma. J Korean Med Sci 2010, 25(2):330-332.

4. Tazi K, Ehirchiou A, Karmouni T, Maazaz K, el Khadir K, Koutani A, Ibn Attiya Al, Hachimi M, Lakrissa A: Inflammatory pseudotumors of the kidney: a case report. Ann Urol (Paris) 2001, 35(1):30-33.

5. Selvan DR, Philip J, Manikandan R, Helliwell TR, Lamb GH, Desmond AD: Inflammatory pseudotumor of the kidney. World J Surg Oncol 2007, 5:106.

6. Arber DA, Kamel OW, van de Rijn M, Davis RE, Medeiros LJ, Jaffe ES, Weiss LM: Frequent presence of the Epstein-Barr virus in inflammatory pseudotumor. Hum Pathol 1995, 26(10):1093-1098.

7. Brittig F, Ajtay E, Jaksó $P$, Kelényi G: Follicular dendritic reticulum cell tumor mimicking inflammatory pseudotumor of the spleen. Pathol Oncol Res 2004, 10(1):57-60.

8. Tarhan F, Gül AE, Karadayi N, Kuyumcuoğlu U: Inflammatory pseudotumor of the kidney: a case report. Int Urol Nephrol 2004, 36(2):137-140.

9. Gwynn ES, Clark PE: Inflammatory myofibroblastic tumor associated with renal cell carcinoma. Urology 2005, 66(4):880.

10. Petrescu A, Berdan G, Hulea I, Gaitanidis R, Ambert V, Jinga V, Popescu M, Andrei F, Niculescu L: Renal inflammatory myofibroblastic tumor - a new case report. Rom J Morphol Embryol 2007, 48(4):437-442. doi:10.1186/1752-1947-5-411

Cite this article as: Khallouk et al:: Inflammatory pseudotumor of the kidney: a case report. Journal of Medical Case Reports 2011 5:411.

\section{Submit your next manuscript to BioMed Central and take full advantage of:}

- Convenient online submission

- Thorough peer review

- No space constraints or color figure charges

- Immediate publication on acceptance

- Inclusion in PubMed, CAS, Scopus and Google Scholar

- Research which is freely available for redistribution

Submit your manuscript at www.biomedcentral.com/submit
C Biomed Central 